\title{
THỰC TRẠNG VÀ GIẢI PHÁP CHO VẤN ĐỀ Ô NHIỄM KHÔNG KHÍ Ở VIẸTT NAM
}

\author{
Nguyễn Thị Hạnh, Phùng Đức Mạnh, Nguyễn Trúc Thảo My, Nguyễn Mai Linh, Nguyễn \\ Đức Huy, Nguyễn An Bình, Nguyễn Đặng Linh Chi, Vũ Ánh Tuyết, Đặng Thanh Xuân, \\ Nguyễn Thành Như Ý
}

Đại học Quốc gia Hà Nội

Ngày 07 tháng 01 năm 2022

Preprint DOI: $\underline{10.31219 / \text { osf.io/sv3gk }}$

Trong thời kỳ công nghiệp hóa hiện đại hóa một trong những bài toán mang tính thời sự được đặt ra là vấn đề ô nhiễm, đặc biệt là thực trạng ô nhiễm không khí tại Việt Nam và trên cả thế giới. Theo thống kê của Tổ chức Y tế Thế giới (WHO), ô nhiễm không khí là nguyên nhân gây ra gần 7 triệu (Jillian Mackenzie \& Jeff Turrentine, 2016) ca tử vong trên toàn cầu mỗi năm. Viện Health Effects Institute (HEI) đã ghi nhận hơn 95\% (Ý, 2020) dân số thế giới đang phải đối mặt với bầu không khí ô nhiễm, trên $60 \%$ (Ý, 2020) người dân phải sống ở những môi trường không đáp ứng được tiêu chuẩn cơ bản của WHO. Ở nước ta, một số dữ liệu đã chỉ ra rằng các thành phố lớn của Việt Nam (Hà Nội) đứng trong nhóm 10 (Nguyen et al., 2021; Van Khuc et al., 2020; Q. Vuong et al., 2021; Ý, 2020) nước ô nhiễm không khí hàng đầu Châu Á.

Về nguyên nhân, 2 khía cạnh chính ảnh hưởng đến sự ô nhiễm này là do hoạt động con người và do tự nhiên.Trong đó, nguyên nhân tự nhiên được hình thành từ các núi lửa, cháy rừng, bão bụi và trong các quá trình phân hủy xác của động, thực vật. Còn "Nguyên nhân nhân tạo chủ yếu là do hoạt động của các nhà máy công nghiệp, đốt thải nhiên liệu sinh ra các chất sulfur dioxide, do phương tiện giao thông đông đúc và bên cạnh đó là hoạt động của con người”(Pandey, 2016). Những điều trên đã gây ảnh hưởng nặng nề đến ô nhiễm không khí, không chỉ gây hại cho sức khỏe con người mà còn cho môi trường mà chúng ta đang sống, cụ thể là các hiện tượng: Bụi mù, suy giảm tầng ozone, mưa axit, .... Vì vậy, để bảo vệ không khí nhưng vẫn đảm bảo tiến trình công nghiệp hóa - hiện đại hóa diễn ra, chúng ta cần sử dụng những thiết bị, máy móc hiện đại hơn, hạn chế sử dụng những nhiên liệu độc hại. Đồng thời cần đẩy mạnh phát triển và đầu tư các phương pháp xử lý khí lọc không khí và trồng nhiều cây xanh. 


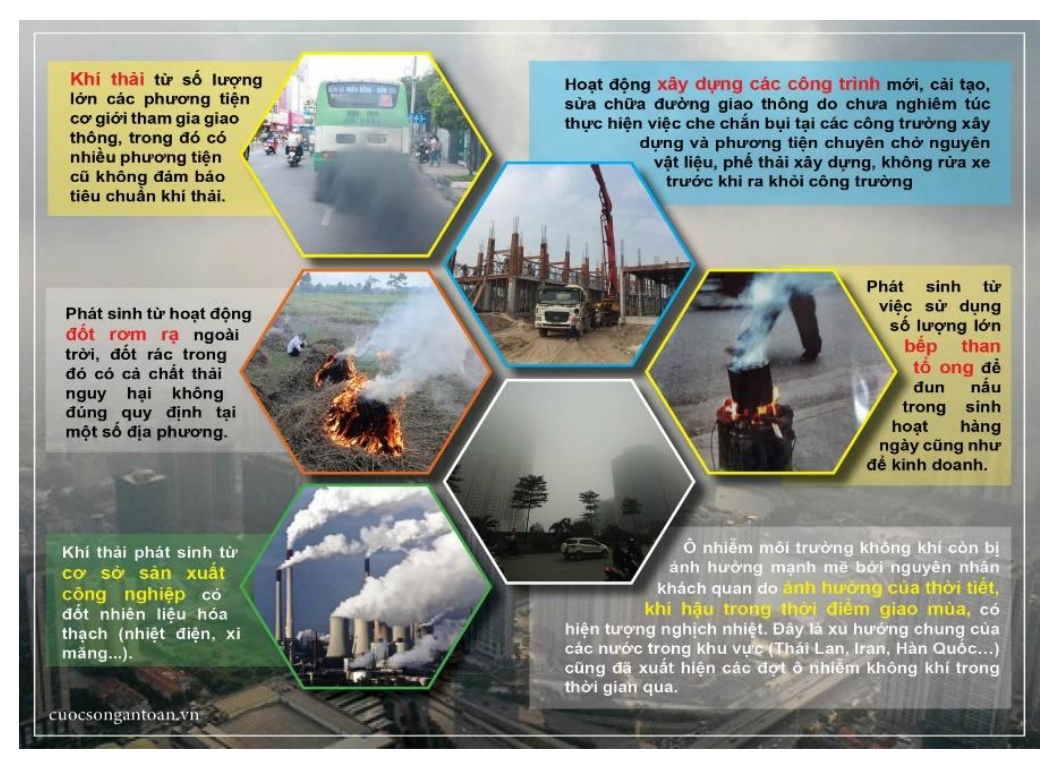

Hình 1: Một số nguyên nhân gây ra ô nhiêm không khí

Nguồn: (Ngân, 2019)

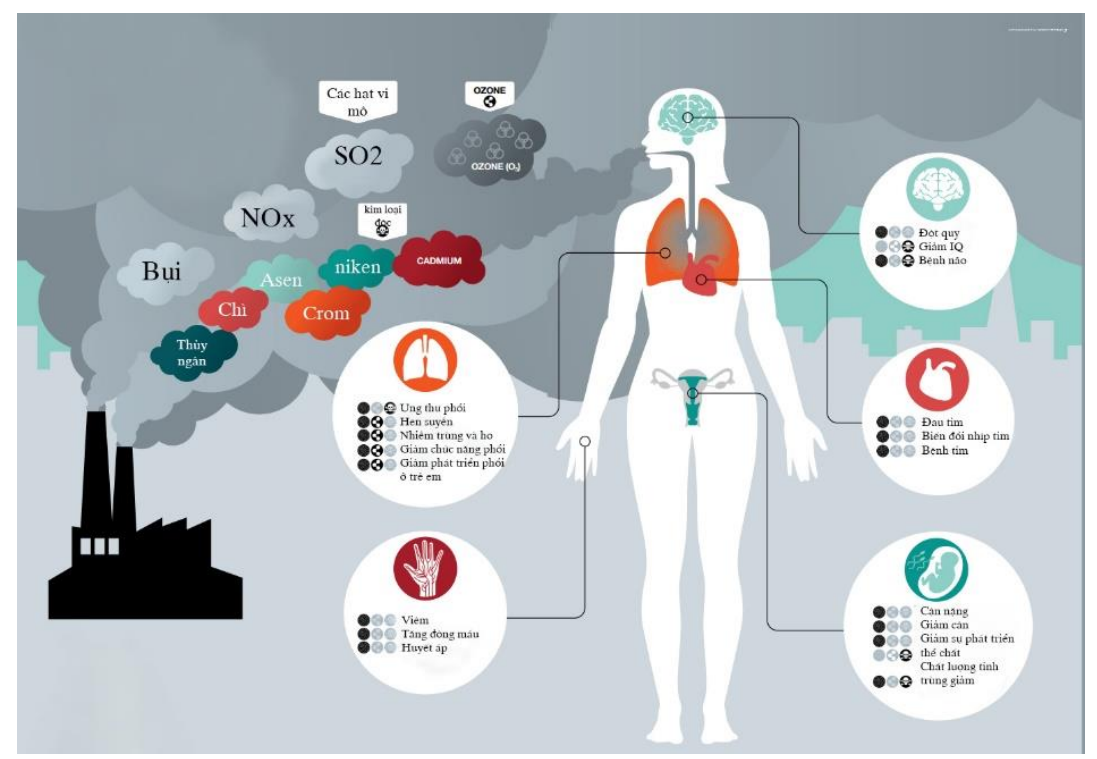

Hình 2: Nhũng tác hại của ô nhiễm không khi lên sức khỏe con người

Nguồn: (BBT, 2019)

Trong những năm qua, con người đã có những cố gắng nhất định để cải thiện và ngăn chặn hiện tượng ô nhiễm không khí đang diễn ra ngày một trầm trọng hơn trên toàn cầu. Song song với những nỗ lực đó, chúng ta vẫn còn gặp phải không ít khó khăn, thách thức tiêu biểu là những tồn đọng trong Hội nghị khí hậu COP26. Thứ nhất là "Quy tắc về Thỏa thuận Paris chura hoàn chỉnh" Thỏa thuận này nói về việc thiết lập thị trường phát thải carbon và cho phép các nước trao đổi tín chỉ carbon, khiến các bên lo ngại. Cùng với rào cản ngôn ngữ và nội dung giữa các quốc gia do Điều 6 chứa quá nhiều thông tin kỹ thuật, việc các quốc gia lợi dụng các lỗ hổng khiến việc ước tính lượng khí nhà kính bị cắt giảm hoặc đưa ra thị trường là không thể Thứ hai đó là vấn đề “Không có quỹ trách nhiệm”. Điều này không có lợi cho nhiều quốc gia đang phát triển, khiến họ cảm thấy thất vọng bởi họ muốn có quỹ dành để bồi thường thiệt hại do khủng hoảng khí hậu gây ra. Tuy Hiệp ước Khí hậu Glasgow công nhận những "tổn thất và 
thiệt hại” của các quốc gia nhưng cũng chỉ kêu gọi đối thoại nhiều hơn chứ không lập quỹ. Điều này có thể hiểu rằng quỹ này có thể mất hàng năm mới được thành lập với điều kiện các bên có ý định(T. D. T, 2021).

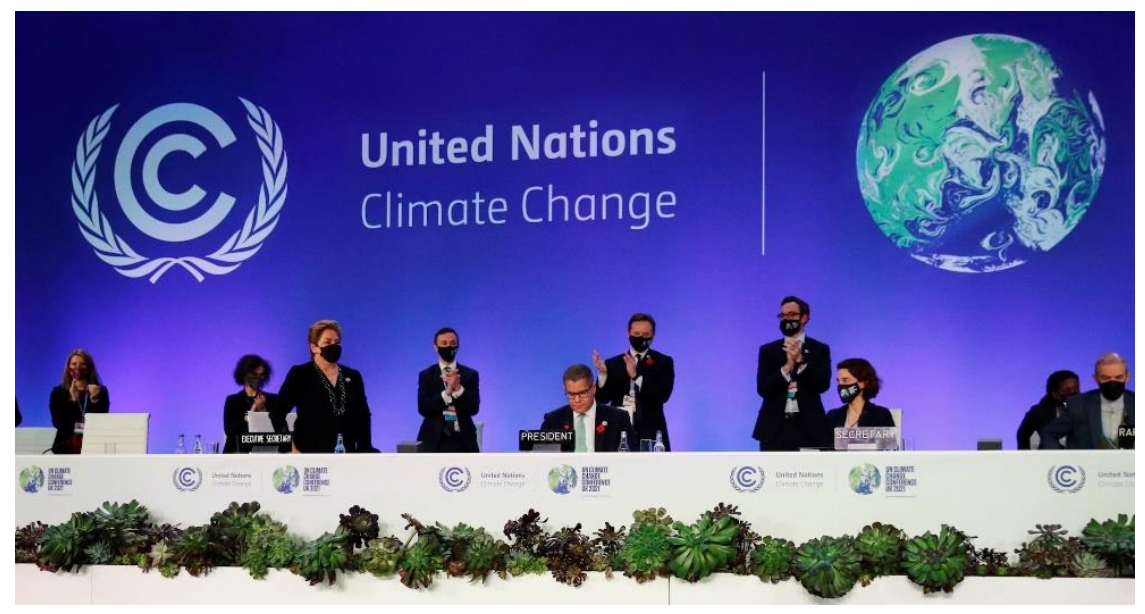

Hình 3: Hội nghị khi hậu COP26

Nguồn: (UNEP, 2021)

Ô nhiễm không khí đã và đang là một vấn đề nan giải toàn cầu, không chỉ là vấn đề riêng về môi trường mà còn là vấn đề về quyền của con người. David $\mathrm{R}$. Boyd, báo cáo viên về nhân quyền và môi trường của tổ chức Liên Hợp Quốc về quyền con người phát biểu về thực trạng trên: "Con số 7 triệu người chết do ô nhiễm không khí hàng năm nhiều hơn tổng số tử vong do chiến tranh, giết người, bệnh lao, HIV, AIDs và sốt rét cộng lại”'(S. Larson, 2019). Cũng theo một thống kê mới nhất của tổ chức Liên Hợp Quốc về môi trường nói rằng: "Nếu bạn sống ở một thành phố ở quốc gia có thu nhập thấp hoặc trung bình, cơ hội hít thở không khí sạch là rất thấp — 97\% thành phố ở những quốc gia này không đáp ứng các nguyên tắc về chất lượng không khí'”(U. N. E. Programme, 2019).

Tất cả các thông tin và thống kê trên đều cho rằng ô nhiễm không khí ảnh hưởng cực lớn tới sức khỏe của con người, đặc biệt là trẻ nhỏ, đối tượng cần phải được hưởng quyền lợi nhiều nhất. Không chỉ ô nhiễm không khí mà tất cả những hành động mang tính phá hoại môi trường đều đồng nghĩa với việc họ đang tự cướp đi quyền lợi cơ bản của chính mình. Trong nhiều thập kỷ, các chính phủ đã coi ô nhiễm không khí như một vấn đề môi trường, gần đây nó đã bắt đầu được coi là một vấn đề sức khỏe. Ô nhiễm không khí ở quy mô ngày nay rõ ràng đã vi phạm các quyền về cuộc sống và sức khỏe, quyền của trẻ em và quyền được sống trong một môi trường an toàn, trong sạch, lành mạnh và bền vững(D. R. Boyd, 2019). Theo nguyên tắc 1 của Tuyên bố Stockholm (1972) của tổ chức y tế thế giới WHO, nhằm thiết lập nền tảng để liên kết các quyền con người, sức khỏe, và bảo vệ môi trường, tuyên bố rằng: "Con người có quyền cơ bản về tự do, bình đẳng và các điều kiện sống đầy đủ, trong một môi trường có chất lượng cho phép một cuộc sống đúng đắn và hạnh phúc"(Shelton, 2002). Điều kiện môi trường rõ ràng giúp xác định mức độ mà mọi người được hưởng các quyền cơ bản về cuộc sống, sức khỏe, đồ ăn và nhà ở, sinh kế và văn hóa truyền thống. 


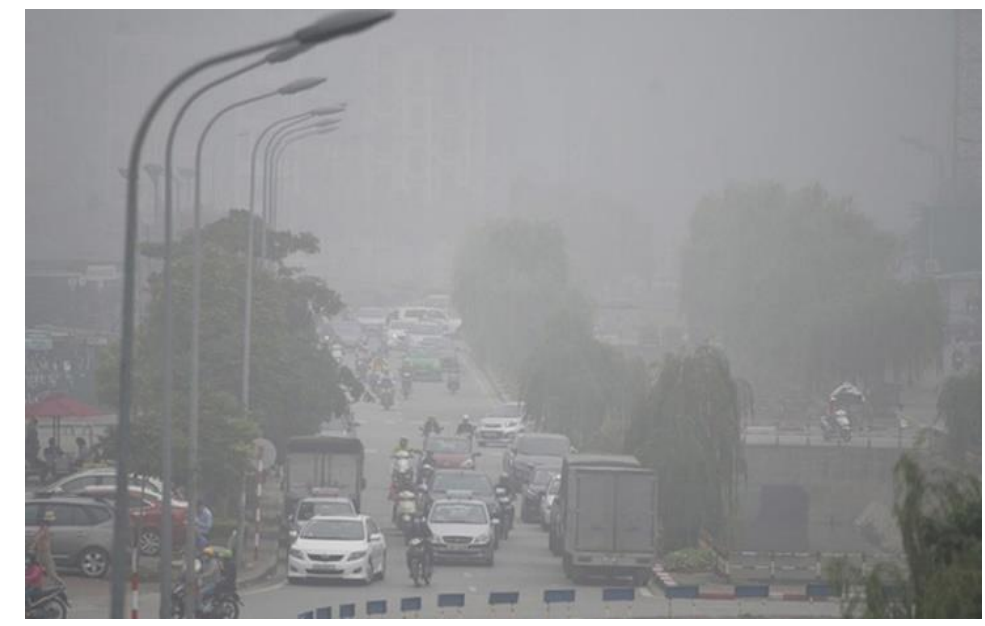

Hình 4: Ô nhiễm không khí ở Hà Nội

Nguồn: (VNA, 2019)

Trước tình hình ô nhiễm không khí nghiêm trọng, Chính phủ mỗi quốc gia có những cách giải quyết khác nhau. Theo Clean Air Fund, tại Hoa Kỳ, sau khi ban hành Đạo luật Không khí sạch vào năm 1970 thì lượng phát thải của sáu chất ô nhiễm phổ biến tại Quốc gia này đã được giám sát theo Đạo luật Không khí sạch và giảm trung bình 69\% trong khi GDP tăng 238\% (Baidu.com, 2015). Ở Ấn Độ, Ủy ban Giám sát chất lượng không khí New Delhi khuyến cáo tất cả các cơ sở giáo dục nên tạm thời đóng cửa cho tới khi nhận được thông báo mới do sự ô nhiễm không khí tới mức trầm trọng, khó kiểm soát (M. Tâm, 2021). Còn tại Việt Nam, Bộ Tài nguyên và Môi trường đề xuất ban hành một loạt biện pháp cấp bách để khắc phục vấn đề ô nhiễm không khí như: xây dựng, triển khai kế hoạch quản lý chất lượng môi trường không khí của địa phương...(V. Sơn, 2020) Mới đây, ngày 23/11/2021, Thủ tướng Chính phủ đã ban hành quyết định 1973/QĐ-TTg 2021 về "Kế hoạch quốc gia về quản lý chất lượng môi trường không khí giai đoạn 2021-2025”(Phủ, 2021).

Dựa trên các thực tiễn trên, sinh viên đề ra giải pháp như sau. Thứ nhất, cần ban hành Luật riêng về vấn đề ô nhiễm không khí. Thứ hai, cần nghiêm ngặt trong các quy định, nghị định về việc tuân thủ theo các chỉ số về không khí mà thế giới thống nhất, đề ra trong lĩnh vực kinh tế, đời sống. Bên cạnh đó, xây dựng văn hóa môi trường (Khuc, 2022; Q.-H. Vuong, 2021; Q. Vuong, 2020; Q. H. Vuong, 2021; Q. H. et al. Vuong, 2018), chuyển đổi văn hóa môi trường là cần thiết và cấp bách. Theo đó đối với mỗi người dân, cần có các giải pháp sáng tạo để nâng cao ý thức, hành vi trong việc bảo vệ môi trường không khí, tránh những xâm hại gây ô nhiễm không khí, làm ảnh hưởng tới sức khỏe của con người (Vuong, Q. H., 2022; Q. H. Vuong \& Napier, 2014).

Trong thời đại công nghệ số phát triển, con người không thể tránh được sự tàn phá của tự nhiên. Và tất cả các quốc gia trên thế giới đều nhận biết được điều đó, vì vậy các quốc gia đã đưa ra những điều luật riêng và tham gia vào các liên minh chung để ngăn chặn việc phá hoại môi trường trở thành một vấn nạn không thể sửa chữa được. Qua việc đưa ra những thực trạng của xã hội, nhóm chúng em đã cho mọi người thấy một góc nhìn chân thực nhất về tình trạng ô nhiễm không khí và những biện pháp của các quốc gia về vấn nạn này.

\section{Reference materials}


Baidu.com. (2015). Image source. Baidu.Com.

BBT. (2019). Ảnh hưởng của ô nhiễm không khí với sức khỏe con người. Activatedcarbon.Vn. https://activatedcarbon.vn/anh-huong-cua-o-nhiem-khong-khi-voi-suc-khoe-con-nguoi.htm

D. R. Boyd. (2019). The human right to breathe clean air. National Center for Biotechnology Information. https://www.ncbi.nlm.nih.gov/pmc/articles/PMC6923778/

Jillian Mackenzie \& Jeff Turrentine. (2016). Air pollution everything you need now. Natural Resources Defense Council. https://www.nrdc.org/stories/air-pollution-everything-you-need-know\#sec1

Khuc, Q. Van. (2022). Về khả năng ứng dụng của hệ xử lý thông tin 3D và nguyên lý bán dẫn giá trị trong tìm kiếm giải pháp cho vấn đề ô nhiễm môi trường và biến đổi khí hậu ở Việt Nam. Tạp Chí Kinh Tế và Dư Báo, 1, 1-5. https://kinhtevadubao.vn/ve-kha-nang-ung-dung-cua-he-xu-ly-thongtin-3d-va-nguyen-ly-ban-dan-gia-tri-trong-tim-kiem-giai-phap-cho-van-de-o-nhiem-moi-truongva-bien-doi-khi-hau-o-viet-nam-20840.html

M. Tâm. (2021). Ấn Độ : New Delhi đóng cửa trường học do ô nhiễm không khí nghiêm trọng. Việt Nam Plus. https://www.vietnamplus.vn/an-do-new-delhi-dong-cua-truong-hoc-do-o-nhiemkhong-khi-nghiem-trong/754445.vnp

Ngân, H. (2019). cuocsongantoan.vn. Cuocsongantoan.Vn. https://cuocsongantoan.vn/dau-la-nguyennhan-chinh-gay-o-nhiem-bui-trong-moi-truong-khong-khi-29796.html

Nguyen, T. C., Le, H. T., Nguyen, H. D., Le, T. H., \& Nguyen, H. Q. (2021). Estimating economic benefits associated with air quality improvements in Hanoi City: An application of a choice experiment. Economic Analysis and Policy, 71, 420-433. https://doi.org/10.1016/j.eap.2021.06.009

Pandey, A. \& S. P. (2016). A dual-route approach to orthographic processing. Frontiers. http://www.frontiersin.org/language_sciences/10.3389/fpsyg.2011.00054/full

Phủ, T. tướng C. (2021). Quyết định 1973/QĐ-TTg 2021 Kế hoạch quốc gia về quản lý chất lượng môi trường không khí giai đoạn 2021-2025. In Thu Viện Pháp Luật. https://thuvienphapluat.vn/vanban/Tai-nguyen-Moi-truong/Quyet-dinh-1973-QD-TTg-2021-Ke-hoach-quoc-gia-ve-quan-lychat-luong-moi-truong-khong-khi-495464.aspx

S. Larson. (2019). Time to see air pollution as a human right threat: U.N. REUTERS. https://www.reuters.com/article/us-health-pollution-rights-idUSKCN1QL268

Shelton, D. (2002). Human rights, health \& environmental protection : linkages in law \& practice a background paper for the world health organization. Notre Dame LOndon Law Centre, 1, 1-24. https://www.who.int/hhr/information/Human_Rights_Health_and_Environmental_Protection.pd $\mathrm{f}$

T. D. T. (2021). Điểm lại những thành công và thất bại của hội nghị khí hậu COP26. Báo Tin Tức. https://baotintuc.vn/the-gioi/diem-lai-nhung-thanh-cong-va-that-bai-cua-hoi-nghi-khi-haucop26-20211115170816281.htm

U. N. E. Programme. (2019). Clean air as a human right. UNEP. https://www.unep.org/news-andstories/story/clean-air-human-right

UNEP. (2021). COP26 ends with agreement but falls short on climate action. UNEP. https://www.unep.org/news-and-stories/story/cop26-ends-agreement-falls-short-climate-action

V. Sơn. (2020). Khắc phục nạn ô nhiễm không khí: Bộ Tài nguyên và Môi trường đề xuất ban hành một loạt biện pháp cấp bách. Báo Pháp Luât. https://baophapluat.vn/khac-phuc-nan-o-nhiem-khongkhi-bo-tai-nguyen-va-moi-truong-de-xuat-ban-hanh-mot-loat-bien-phap-cap-bachpost348554.html

Van Khuc, Q., Phu, T. V., \& Luu, P. (2020). Dataset on the Hanoian suburbanites' perception and 
mitigation strategies towards air pollution. Data in Brief, 33, 106414. https://doi.org/10.1016/j.dib.2020.106414

VNA. (2019). Hà Nội residents worry about air pollution. Vietnamplus. https://en.vietnamplus.vn/hanoi-residents-worry-about-air-pollution/149105.vnp

Vuong, Q. H., et al. (2022). Covid-19 vaccines production and societal immunization under the serendipity-mindsponge-3D knowledge management theory and conceptual framework. Humanities and Social Sciences Communications, 9, forthcoming.

Vuong, Q.-H. (2021). Western monopoly of climate science is creating an eco-deficit culture. Economy, Land \& Climate Insight, 11, 1-9. https://elc-insight.org/western-monopoly-of-climat

Vuong, Q. (2020). From children's literature to sustainability science, and young scientists for a more sustainable Earth From children' s literature to sustainability science, and young scientists for a more sustainable Earth. Journal of Sustainability Education, 24(December), 2019-2021.

Vuong, Q. H. (2021). The semiconducting principle of monetary and environmental values exchange. Economics and Business Letters, 10(3), 284-290. https://doi.org/10.17811/ebl.10.3.2021.284-290

Vuong, Q. H. et al. (2018). Cultural additivity: behavioural insights from the interaction of Confucianism, Buddhism and Taoism in folktales. Palgrave Communications, 4(143). https://doi.org/10.1057/s41599-018-0189-2

Vuong, Q. H., \& Napier, N. K. (2014). Making creativity: the value of multiple filters in the innovation process. International Journal of Transitions and Innovation Systems, 3(4), 294-327. https://doi.org/10.1504/ijtis.2014.068306

Vuong, Q., Phu, T. V., Le, T. T., \& Khuc, Q. Van. (2021). Exploring Inner-City Residents' and Foreigners' Commitment. Data, 6(39). https://doi.org/10.17632/8sv4j2r9wk.2

Ý, L. T. (2020). Ô nhiễm không khí: giải pháp toàn cầu và ở Việt Nam trong phát triển bền vững. GREENID. http://greenidvietnam.org.vn/o-nhiem-khong-khi-giai-phap-toan-cau-va-o-viet-namtrong-phat-trien-ben-vung.html 